\title{
Geografia de Relações: um continuum interior-exterior no corpo
}

\author{
Vivian Vieira Peçanha Barbosa \\ Universidade Federal de Uberlândia - UFU, Uberlândia/MG, Brasil \\ E-mail: vivian.iarteufu@gmail.com
}

$\mathrm{O}$ artigo indaga a ideia de continuum interior-exterior a partir das noções labanianas de dance sense, movimento-pensamento, Impulso Interno [Antrieb] e Esforço como modo de refletir aspectos cruciais ao processo de criação coreográfica autoral de $R e$ versa. Foco da pesquisa de doutorado defendida pela autora em 2019, Reversa traz como uma de suas questões o tensionamento entre dentro e fora, visível e invisível, ponto em que o pensamento de Rudolf Laban sobre as qualidades relacionais do corpo em sua visão holística se mostrou relevante. Destaco no texto a discussão sobre modos de compreender e complexificar a relação entre vida interior - em seus particulares movimentos, sensações, sentimentos, impressões - e gesto, fundamentada principalmente em aspectos pontuais do pensamento labaniano e na experiência pessoal com a criação e apresentação de Reversa.

Dance sense. Movimento-pensamento. Impulso Interno. Esforço. Criação Coreográfica.
The article presents an inquiry into the idea of an inner-outer continuum based on the Labanian notions of dance sense, movement-thinking, Inner Impulse [Antrieb] and Effort as a way of reflecting crucial aspects of the authorial choreographic creation process of Reversa. Focus of the doctoral research defended by the author in 2019, Reversa brings the tension between inside and outside, visible and invisible as one of its questions. In this point, Rudolf Laban's thought about the relational qualities of the body in his holistic view showed to be relevant. In this text I highlight the discussion about ways of understanding and complexifying the relationship between inner life - in its particular movements, sensations, feelings, impressions - and gesture, mainly based on specific aspects of Labanian thought and on the personal experience with Reversa's performance and creation.

Keywords

Dance Sense. Movement-thinking. Inner Impulse. Effort. Choreographic Process. 
Figura 1 - Autora em Reversa. Sala Aberta 2019, Universidade Federal de Uberlândia, MG.

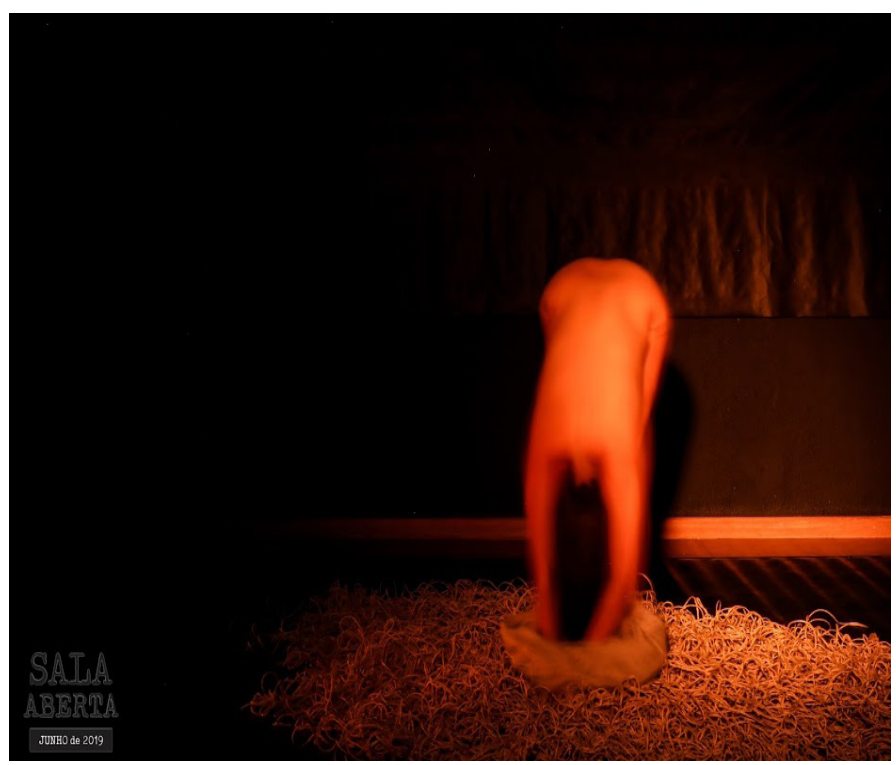

Fonte: Arquivo do Curso de Dança da Universidade Federal de Uberlândia. Junho de 2019. Fotografia: Alexis F.S.

Esvazio-me. Vibro. Deixo entrever sutilezas que me passam e transformam as teias do corpo. Através dos olhos, poros, películas e buracos o corpo se desdobra e me desdobro. O gesto, embora minuciosamente construído, não é comandado, mas cultivado em outro nível de conexão entre visível e invisível. O que há nesse diálogo entre acontecimentos internos e externos enquanto danço Reversa'?

Tomemos alguns aspectos do pensamento de Rudolf Laban (1879-1958) para desenrolar alguns fios desse diálogo. Sabemos que uma de suas contribuições mais importantes para o campo da dança consistiu em atribuir linguagem ao movimento e seus intrínsecos aspectos: terminologias que vêm permitindo compreender e conectar a experiência concreta às palavras, abrindo outras janelas de compreensão na dança para além de passos e gestos codificados. Mesmo assim, Laban sempre retornou ao tema da insuficiência das palavras e descrições para abordar a dança e o gesto humano em um sentido mais amplo.

Em Choreutics (LABAN, 2011a), o artista e pensador austro-húngaro anuncia que "O complexo

1 Performance solo de dança desenvolvida pela autora como parte do doutorado em Artes Cênicas pela Universidade Federal da Bahia, com período sanduíche realizado na Middlesex University, Londres, por meio de financiamento CAPES/PDSE. É possível acessar trecho do trabaIho em https://www.youtube.com/watch?v=Y-9HqJ8jtKo. sentimento que temos ao observar ou executar um movimento não pode ser descrito em palavras." ( $p$. 47, tradução minha), e que "[...] na dança, os traços-forma e seus desdobramentos dinâmicos devem falar por si mesmos." (p. 93, tradução minha)². Já em The Mastery of Movement (LABAN, 2011b), Laban declara que "Frequentemente é impossível organizar o conteúdo de uma dança em palavras, embora sempre se possa descrever o movimento." (p. 3, tradução minha) e que "Os desenhos visíveis da dança podem ser descritos em palavras, mas seu significado mais profundo é verbalmente inexprimível." (p. 21, tradução minha) ${ }^{3}$. Também no livro $A$ vision of dynamic space (LABAN, 1984), diz o autor que:

"A dança e seus efeitos no espectador são uma entidade que transcende as interpretações verbais, embora as funções corporais e mentais usadas nela sejam perfeitamente descritíveis em termos de padrão espacial e ritmo, assim como a música é descrita em termos de padrão de som e ritmo." (LABAN, 1984, p. 48, tradução minha) ${ }^{4}$.

Mas o que seria essa partícula inapreensível do movimento? Que experiências são estas que podem transbordar, rasgar, suplantar, emudecer palavras?

2 No original: "The complex feeling we have when seeing or executing a movement cannot be described in words." (p. 47); "[...] in dance, the trace-forms and their dynamic unfolding must speak for themselves." (p. 93).

3 No original: "It is frequently impossible to outline the content of a dance in words, although one can always describe the movement." (p. 3); "The visible patterns of dance can be described in words, but its deeper meaning is inexpressible verbally." (p. 21).

4 No original: "Dance and its effects on spectator is an entity transcending verbal interpretations although the bodily and mental functions used in it are perfectly describable in terms of space pattern and rhythm, just as music is described in terms of sound-pattern and rhythm." (p. 48). 
Figura 2 - Autora em Reversa. Conferência Laban 2018. Centro Coreográfico da Cidade do Rio de Janeiro, RJ.

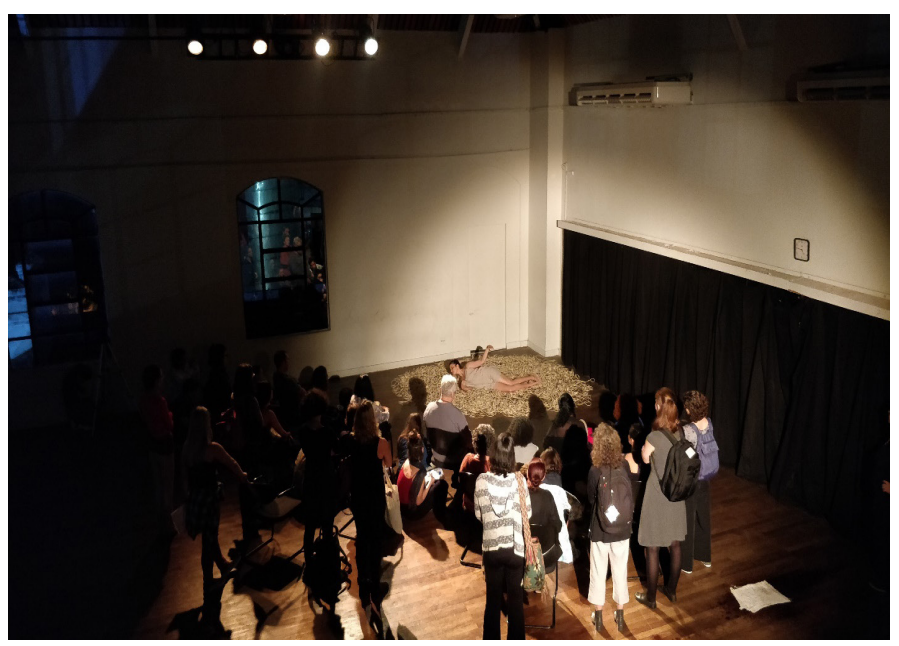

Fonte: Arquivo pessoal. Agosto de 2018. Fotografia: Jinn Tsay.

\section{Tensões, sensações, impressões - dance sense e movement-thinking}

Logo após assistir uma das apresentações de Reversa ${ }^{5}$, alguém da plateia pergunta o que se passa em minha cabeça enquanto danço, como se dá o pensamento. Digo que não considero o pensamento somente uma atividade intelectual, mas que há outros níveis e modos de pensar e de lidar com "o que se passa na cabeça", e não somente nela. Ao responder à pergunta, falo de minha experiência conectando movimento, respiração e meditação do Yoga, mas também lembro da dance sense e do pensamento-movimento [movement-thinking] de Laban e em como esses termos tangenciam esses outros modos de pensar, mais próximos à subjetividade corpórea.

Dance sense ${ }^{6}$, termo que aparece no primeiro livro publicado de Laban, O Mundo do dançarino [Die Welt des Tänzers], remete àquilo que os bailarinos percebem enquanto dançam. Uma percepção que

5 Realizada na Hamilton House em Bristol, Inglaterra, em 5 de julho de 2018.

6 Dance sense poderia ser traduzido para o português como sensação da dança, sentido da dança, percepção da dança, sensibilidade da dança. Preferi manter a expressão em inglês por compreender que talvez nenhuma palavra portuguesa possa ser compatível com o significado que Laban almejava que, em minha leitura, contém todas as expressões em português mencionadas, bem como todos esses significados das expressões mencionadas parecem estar contidos na palavra sense. integra aspectos sensoriais, emocionais e intelectuais em uma unidade, conforme tradução para o inglês do texto original alemão, realizada por Sachsenmaier e McCaw (MCCAW, 2011). O que Laban chamou como dance sense nesse texto de 1920 tem a ver com os modos como os artistas processam os acontecimentos a partir das inúmeras sensações e tensões que tais acontecimentos geram.

Quem é capaz de transformar as impressões do ambiente em um sentimento físico-espiritual-mental de tensão tem aptidão para a dança. Se o dançarino percebe uma forma por meio da visão ou do toque, se ele ouve uma onda sonora, se ele pensa um pensamento, então uma tensão ou uma sequência de tensões surge dentro dele, a partir da qual ele tira algumas conclusões sobre a natureza e o caráter do fenômeno diante dele. Eu gostaria de chamar isto de dance sense. Hoje, essa dance sense está atrofiada porque não é praticada o suficiente - apenas o artista a tem, na medida em que ela entra na equação como um elemento que traz conhecimento para o mundo de sua vontade, de suas emoções e de seus pensamentos. Essa percepção de dança integra toda a percepção sensorial, emocional e intelectual em uma unidade. (LABAN apud MCCAW, 2011, p. 48, tradução minha) ${ }^{7}$.

Laban chama atenção, aqui, para a construção de uma sensibilidade no ato de perceber-dançar. Ou seja, mais do que a aptidão para passos marcados de uma dança, a aptidão para lidar e transformar as tensões geradas com as impressões é o que faz desabrochar a dance sense. Isto faz com que reste algo de não completamente capturável no movimento, algo de enigmático nessa relação de tensão e de "sequência de tensões" que

\footnotetext{
7 No original: "Whoever can transform impressions from the environment into a physical-spiritual-mental feeling of tension has dance talent. If the dancer perceives a form by means of sight or touch, if he hears a sound wave, if he thinks a thought, then a tension or a sequence of tensions arise within him from which he draws certain conclusions about the nature and character of the phenomenon before him. I should like to call this dance sense. Today this dance sense is atrophied because it is not practised enough - only the artist has it to the degree that it comes into the equation as a knowledge-bringing element for the world of his will, emotions and thoughts. This dance perception integrates the whole sensory, emotional and intellectual perception into a unit."
} 
englobam mais que o movimento visível. Uma paisagem interna de impressões que, de modo singular, integram o dançarino consigo e com o mundo.

Três décadas mais tarde, em The Mastery of Movement (LABAN, 2011b), primeiramente publicado em 1950 como The Mastery of Movement on the Stage, Laban nomeou o que os bailarinos experimentam enquanto dançam como "pensamento-movimento": modos particulares de modular e articular um pensamento diretamente enlaçado ao fazer ${ }^{8}$. A união das duas palavras, conectadas por traço, hífen, anuncia certa inteligência do ato que aponta para um pensamento que não se define como submissão de algo a um processo de reflexão ou raciocínio lógico, mas que conecta movimento interior e exterior através de impulsos, como sensibilidade direta do mover no mover.

O pensamento-movimento pode ser considerado como uma reunião de impressões de acontecimentos na própria mente, para a qual falta uma nomenclatura. Este pensamento não serve, como o pensamento por palavras, de orientação para o mundo externo, mas sim à orientação perfeita do homem em seu mundo interior, no qual os impulsos continuamente surgem e buscam uma saída no fazer, no atuar e no dançar. (LABAN, 2011b, p. 15) ${ }^{9}$.

Ou seja, o pensar-mover tem relação direta com os movimentos intuitivos de um mundo interior, criando um saber prático que, em minha visão, demanda uma abertura e uma atenção aos menores acontecimentos que, por sua vez, encontram saídas no fazer que potencialmente transformam novamente os impulsos e a paisagem interior que lhe deram vida. Trata-se de um pensar que se faz na ação enquanto ação, e que não é, portanto, o pensar categorizante, descritivo e interpretativo do intelecto, mas o pensar próprio da dinâmica dos órgãos, músculos

8 Pensamento-movimento foi traduzido como "pensar por movimentos" por Anna Maria Barros De Vecchi e Maria Sílvia Mourão Netto em Domínio do Movimento (LABAN, 1978, p. 42), livro originalmente publicado em 1950, e, ainda, traduzido por Launay (1997) em sua tese como "pensée motrice" (pensamento motor).

9 No original: "Movement-thinking could be considered as a gathering of impressions of happenings in one's own mind, for which nomenclature is lacking. This thinking does not, as thinking in words does, serve orientation in external world, but rather it perfect man's orientation in his inner world in which impulses continually surge and seek an outlet in doing, acting and dancing." e ossos, do peso, do espaço, do fluxo e do tempo. Esse corpo, seguindo os tais impulsos que Laban evoca, não é, portanto, o corpo que submete objetos à análise. A existência e o saber desse corpo é anterior à essa submissão, como o é na consciência pré-reflexiva pensada por Merleau-Ponty (2006).

O filósofo francês separa a consciência reflexiva da consciência perceptiva para interrogar esse modo menos tributário ao intelectualismo a partir do qual conhecemos e organizamos o mundo e seus fenômenos. Em Fenomenologia da Percepção, Merleau-Ponty (2006) articula a experiência pré-reflexiva, essa que é da ordem do corpo vivido antes das formulações conceituais, própria da consciência perceptiva, assim como Laban evoca a lida do bailarino com um outro tipo de saber, não mais calcado exclusivamente pelo que ele chama de "pensar em palavras". Embora o autor indique uma integração do pensamento-movimento ao pensar por palavras, a própria criação coreográfica de Reversa demandou o foco ao sentido, ao significado do pensar-mover. Nesse ponto, a cadeia de tensões da dance sense labaniana pareceu se conectar com seu posterior pensamento-movimento, posto que ambos dependem da exploração, tensionamento e processamento de impressões através da atenção, da percepção e do movimento corpóreo.

Volto então à pergunta: o que se passa em minha cabeça enquanto danço? Sinto e permito que muito se passe. Ou melhor, que muito me passe, lembrando Larrosa (2002) e suas reflexões sobre experiência. Mas também muito me passa nos pés, no umbigo, nas pontas dos dedos, nas pálpebras e na nuca, nos joelhos, na língua e nos pulmões. É que o corpo todo pensa enquanto danço. Pensa-move. E nesse meu pensar-mover, um pensamento mais analítico somente pode ser frutífero a posteriori. O movimento, nesse caso, dialoga com a paisagem interna do corpo não exatamente obedecendo a comandos mentais, através de decisões intelectualmente ponderadas, mas se alinha mais aos pensamentos feitos de sensações, imagens, tensões ${ }^{10}$, impressões e carne.

10 A palavra tensão assume para mim, assim como aludido pela dance sense de Laban, uma qualidade ou estado relacional, mais do que uma ideia de tensionamento muscular, por exemplo. 


\section{Impulso interno e Esforço}

O esforço é a mais sutil e, ao mesmo tempo, mais enigmática manifestação da vida. (Rudolf Laban)

Há uma cadeia complexa de eventos que envolvem o surgimento e o desenvolvimento do movimento humano, algo difícil de ser explicado em termos puramente físicos ou mesmo psicológicos (LABAN, 2011b). Assim, Laban considerou a existência de um movimento interior que seria ponto de origem do movimento corporal visível ou audível, de modo que, para ele, Esforço é a função interna que origina cada movimento (2011b, p. 20), mas que não se resume somente ao ponto de origem, operando também em outras lógicas, como descobri, sejam elas de inversão, sobreposição ou outras formas de complexidade entre exterioridade e interioridade.

Tal interioridade, que aparece nos escritos labanianos ora como vida ou mundo interior, como movimento interno, tensão interna ou paisagem interna, ou ainda, esforço, impulso ou atitude interna, é tema recorrente e intimamente relacionado ao movimento corporal visível, que nem sempre ocorre como decisão deliberada e atrelada a parâmetros mais óbvios de causalidade. O movimento pode tanto acontecer através de uma deliberação consciente como através de uma reação não plenamente deliberada, ou ainda, "[...] sem qualquer contribuição de uma vontade consciente." (LABAN, 2011b, p. 20), como nas shadow-forms ou shadow-movements (LABAN, 2011a; 2011b) $)^{11}$.

11 Shadow-movements ou "movimentos de sombra" na tradução de Vecchi e Netto em Domínio do Movimento (1978), são alterações ou preparações em nossas configurações corporais sobre as quais nem sempre estamos plenamente conscientes. São movimentos corporais que indicam algo de nossas próprias configurações afetivas e de uma paisagem interna, qualitativa e tensional de percepções, pensamentos, sensações e sentimentos. Shadow-movements podem acompanhar ou sombrear um movimento corporal maior e intencional ou estar presentes em pequenos movimentos menos conscientes, sinalizando o interesse de Laban por uma conexão entre vida interior e gesto também pela via inconsciente.
Sobre tamanha complexidade, Laban observa que

A espantosa estrutura do corpo e as incríveis ações que ele pode realizar são alguns dos maiores milagres da existência. Cada fase do movimento, cada pequena transferência de peso, cada gesto de qualquer parte do corpo revela alguma característica de nossa vida interior. Cada movimento origina-se de uma excitação interna dos nervos, causada tanto por uma impressão de sentido imediato, como por uma cadeia complicada de impressões sensoriais anteriormente experimentadas e armazenadas na memória. Esta excitação resulta em um esforço interno voluntário ou involuntário, ou impulso para se mover. (LABAN, 2011b, p. 19, grifo meu) ${ }^{12}$.

Tal esforço interno, ou impulso para se mover, podendo ser mais ou menos voluntário, ajuda a configurar algo crucial à Teoria do Esforço de Laban: uma participação interna no movimento que informa de modo complexo suas infinitas qualidades tensionais e dinâmicas. Para tratar de tal participação interna, Laban utiliza os termos impulse/impulso e inner impulse/impulso interno (1978; 2011b) como sinônimos de Esforço.

Esforço, termo que passou a ser utilizado por volta da Segunda Guerra Mundial, criou então uma espécie de correspondência ao termo alemão antrieb, anteriormente utilizado pelo autor (MALETIC, 1987; BARTENIEFF, 2002; RENGEL, 2003; FERNANDES, 2006), embora a simples tradução dos termos Effort e antrieb não pareça corroborar, à primeira vista, para uma aproximação exata de sentidos.

Antrieb é uma palavra alemã de sentido variável a depender do contexto, mas que pode significar impulso, acionamento, pulsão ou ímpeto. O termo aparece na obra de Vera Maletic (1987), autora alemã que foi uma das alunas de Laban, traduzida como inner impulse, impulso interno. Outra importante discípula de Laban, Irmgard Bartenieff (2002), diz o seguinte sobre o termo: "As atitudes

12 No original: "The astonishing structure of the body and the amazing actions it can perform are some of the greatest miracles of existence. Each phase of movement, every small transference of weight, every single gesture of any part of the body reveals some feature of our inner life. Each Movement originates from an inner excitement of the nerves, caused either by an immediate sense impression, or by a complicated chain of formerly experience sense impressions stored in the memory. This excitement results in the voluntary or involuntary inner effort or impulse to move." 
em relação aos fatores de movimento [Laban] chamou de antrieb em alemão, uma combinação de an (sobre) e trieb (pulsão), representando o desejo do organismo de se tornar conhecido." (2002, p. 51) ${ }^{13}$. Assim, embora tenha utilizado o termo Effort/ Esforço nas décadas finais de sua carreira na Inglaterra, há uma clara aproximação com o sentido original de antrieb. Disso podemos concluir que o Esforço não está somente relacionado a uma qualidade de movimento identificável quando observamos alguém se mover, resumível a uma fisicalidade "pura" ou ao aspecto mais "mecânico" do movimento. Esforço tem a ver, primordialmente, com o estudo do processo através do qual o ser humano gesta e gerencia suas experiências, impressões, projeções e tensões passadas, presentes e futuras e conecta, de modo mais ou menos consciente, tais acontecimentos à sua própria organização corporal, em suas nuances e intensidades - intensidades tais que nem sempre conseguimos articular plenamente em palavras.

\section{Continuum interior-exterior}

Quando danço Reversa, voltar-me para um "dentro" é tão importante como abrir-me para um "fora". As impressões, tensões e impulsos que surgem são frutos desse diálogo mediado pelas camadas, membranas, órgãos, orifícios e películas que tanto delimitam o corpo como promovem esse encontro, essas trocas entre dentro e fora. Ecoando Laurence Louppe (2012, p. 103), acredito que o impulso interno de Laban se elabora em uma "geografia de relações", mais do que se filia, portanto, a uma ideia de exteriorização daquilo que se passa internamente. Como diz a crítica e historiadora de dança francesa:

Não se deve [...] assumir que a relação interior-exterior se resumiria a um processo de exteriorização dos conteúdos ocultos do 'eu'. Na dança, o 'eu' circula. É, de fato, ao mesmo tempo objeto e ator dessa circulação relacional. Os quatro fatores enunciados por Laban [peso, tempo, espaço e fluxo] são de alguma forma as 'chaves' dessa circulação. (LOUPPE, 2012, p. 103).

A própria utilização da expressão "pulsão espacial" por Ciane Fernandes (2015, p. 88), em referência

13 No original: "The attitudes toward the motion factors he called in German antrieb, a combination of an (on) and trieb (drive), representing the organism's urge to make itself known." (p. 51). a antrieb, foi justamente o modo pelo qual a pesquisadora brasileira buscou enfatizar esse impulso em relação, mais do que em uma "existência interna isolada".

O impulso interno não se reduziria, portanto, àquilo que simplesmente se revela desde um "dentro". Ele se expande e se transforma enquanto conexão dialógica, impregnada das alteridades e complexidades próprias de um corpo que tanto doa quanto recebe, que tanto age como é agido, que tanto vê como é visto, que tanto toca como é tocado - como no corpo reflexivo de Merleau-Ponty (2006) -, permitindo circular diferentes energias e com elas tecer seus gestos.

Interessa, nesse sentido, ir além de uma compreensão "psicologizante" ou romantizada da própria ideia de impulso interno e, consequentemente, da própria ideia de expressão na dança, compreensão esta que se ateria meramente ao representar ou demonstrar nos movimentos o que se pensa ou sente, ou a exteriorizar, como diz Laurence Louppe (2012), os "conteúdos ocultos do 'eu'.' A esse respeito o pensamento de Michel Bernard (2006) traz importantes contribuições, já que o filósofo aponta para o perigo de alimentarmos o mito de que há um ser escondido e imprevisível no sujeito que de repente se liberta ao improvisar, em um ato dançado totalmente espontâneo e criativo, destacado de quaisquer condicionamentos.

Há três grandes efeitos do que Bernard chama de "mito da espontaneidade originária", alimentado por uma certa compreensão de improvisação. O primeiro é o de legitimar a ideia de uma liberdade individual pura, desconsiderando o poder que os sistemas e instituições têm sobre os indivíduos. O segundo efeito é o de promover a crença em uma criatividade que funda o eu, o que camuflaria o próprio trabalho de codificação, sistematização e formalização também concernentes aos processos improvisacionais em dança. O terceiro efeito, que é o mais prejudicial do ponto de vista do filósofo, é o de postular uma coincidência do sujeito consigo mesmo, postular "[...] uma identidade primordial revelada numa presença instantânea e [...] anular ou apagar assim a différance que habita a alteridade originária que move nosso sentir." (BERNARD, 2006, p. 130).

Michel Bernard destaca, portanto, que no cerne do gesto criativo há também o confronto e a lida com restrições objetivas e mutáveis que tornam a alteridade do sentir incontornável. Ou seja, é a partir do reconhecimento das restrições e condicionamentos e, ao mesmo tempo, de nossa capacidade inventiva, na fricção desses âmbitos e em suas nuances, que estaremos mais conscientes de que buscar a conexão entre movimento interno 
e externo não significa libertar uma verdade que há dentro de si e que estava escondida ou, tampouco, revelar os tais "conteúdos ocultos do 'eu'".

Isso nos demanda repensar o jargão de que "a dança expressa o que vem de dentro", um certo senso comum que, na perspectiva de Eloisa Domenici (2010), teria suas raízes nas fases romântica e expressionista dessa arte. E embora Laban tenha sido figura decisiva no estabelecimento da dança expressionista alemã [ausdruckstanz], percebo que seu pensamento vai além dessas relações mais óbvias entre interioridade e exterioridade.

Como elucida Anne Suquet,

Para Laban a dança não poderia depender de uma forma de expressionismo qualquer. Se a 'moção' não é separável da 'emoção', como é que poderia expressá-la? A dança não exprime nenhuma interioridade psicológica. Ela é fundamentalmente, segundo a expressão de Laban, o 'poema do esforço' pela qual o ser não cessa de inventar sua própria matéria. (SUQUET, 2011, p. 530).

Logo, nem a negação de uma interioridade e tampouco um simples subjugar do gesto a essa interioridade. Antes, Laban me convoca a pensar o que chamo de continuum interior-exterior, que opera em correspondência direta mas não necessariamente óbvia, permitindo diferentes modos e níveis de participação interna e de transformação dessa relação.

Figura 3 - Autora em Reversa. Middlesex University, Londres.

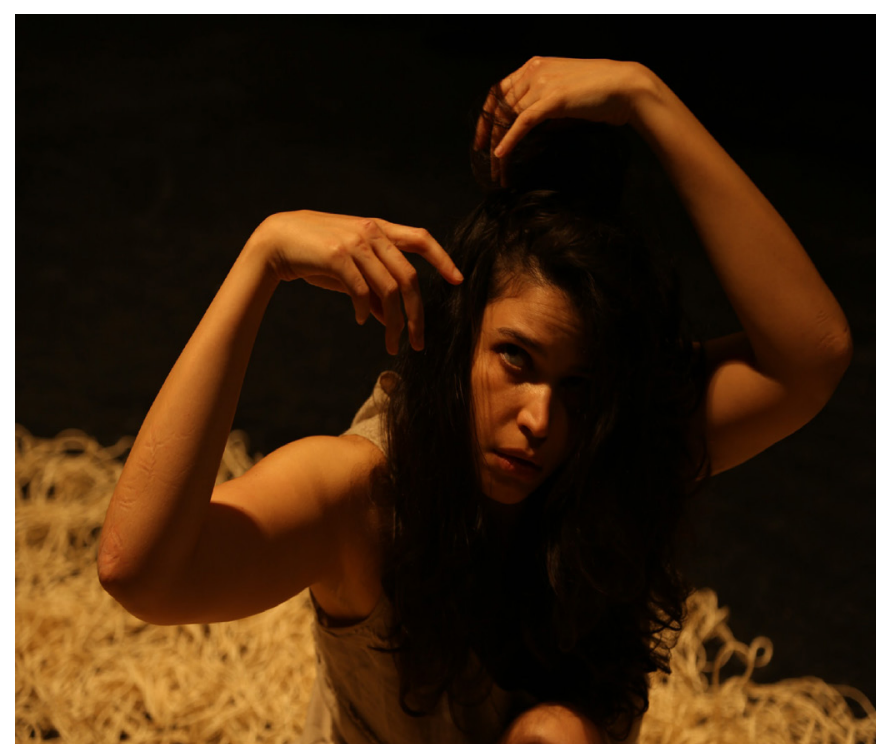

Fonte: Arquivo pessoal. Junho de 2018. Fotografia: Dominique Rivoal.
Não se deve assumir, portanto, a premissa de que sempre há o envolvimento do sujeito como um todo no ato de dançar. Tal envolvimento, suas nuances e desdobramentos, quando desejados, demandam engajamento e um contínuo trabalho do artista sobre si mesmo. Mesmo Laban anunciou ter visto "[...] dançarinos demais que se lançam ao ar sem nenhum sinal de participação interna." (LABAN, 1971 , p. 7$)^{14}$. Isso confirma que há uma trama conectiva entre o dentro e o fora que, ao transformar o gesto e suas tensões, torna visíveis diferentes níveis de engajamento do sujeito no movimento. $E$ é justamente por se situar nesse trânsito interior-exterior que tais tensões tendem a ultrapassar os limites físicos do corpo e ganhar (transformar) o espaço, como pude perceber ao dançar Reversa.

\section{Considerações finais}

Nesse percurso em que o pensamento labaniano indaga minha dança, minha dança também indaga o pensamento labaniano, explorando modos de singularmente encarnar uma experiência de Esforço que entrelace e tensione pontos de contato e transformação entre movimento interno e externo. Aqui, mais do que a aplicação de determinadas qualidades dos fatores de movimento de peso, espaço, fluxo e tempo para a composição de Reversa, busquei algo anterior, algo que pudesse desenrolar alguns fios do gesto enquanto acontecimento intenso, não intelectualmente coordenado, mas cultivado em uma atitude meditativa e paciente que encontrou em práticas respiratórias e meditativas do Yoga, por exemplo, um forte apoio para a exploração de conexões menos óbvias entre vida interior, espaço externo e gesto.

Ao criar e dançar com essa indagação fundamental sobre um continuum interior-exterior e ao estudar textos originais de Laban e de outros autores da dança e do movimento, percebi que noções simplificadoras eram insuficientes para lidar com a complexidade dessas conexões. Ou seja, tanto uma visão que pensa o movimento do corpo de dentro para fora, em via de mão única, como aquela que simplesmente borra dentro e fora a ponto de afirmar que tudo é a mesma coisa, não foram adequadas ou suficientes para criar proximidade com a própria experiência da conexão entre paisagens internas, gesto e espaço exterior enquanto eu dançava. Foi dessa

14 No original: "I have seen all too many dancers who throw themselves into the air without any sign of inner participation." (p. 7). 
maneira que pensar em um continuum que conecta, que transforma, mas que também diferencia interior e exterior, foi crucial, inclusive para discutir e lidar com a sensação de invasão de um espaço no outro, um entrelaçamento que foi construído por meio de muito trabalho de aguçamento da percepção e de meditação em movimento. Somente desse modo foi possível sentir e suportar as forças de dentro e de fora se amalgamando nos gestos, respirações, posturas e suspensões características de Reversa.

\section{Referências}

BARTENIEFF, Irmgard. Body movement: coping with the environment. With Dori Lewis. New York and London: Routledge, 2002.

BERNARD, Michel. Du bon usage de l'improvisation en danse ou du mythe à l'experience. In: BOISSIERE, Anne; KINTZLER, Catherine. (Orgs.) Approche Philosophique du geste dansée. Villeneuve d'Ascq: Presses Universitaires du Septentrion, pp. 129-14, 2006.

DOMENICI, Eloisa. O encontro entre dança e educação somática como uma interface de questionamento epistemológico sobre as teorias do corpo. Pro-Posições, Campinas, v. 21, n. 2 (62), pp. 69-85, maio/ ago. 2010.

FERNANDES, Ciane. O corpo em movimento: o sistema Laban/Bartenieff na formação e pesquisa em artes cênicas. 2a ed. São Paulo: Annablume, 2006.

Princípios em movimento na pesquisa somático-performativa. Resumos do Seminário de Pesquisas em Andamento PPGAC/USP. Editor responsável: Umberto Cerasoli Jr Designação numérica: v.3.1, pp. 81-95, 2015.

LABAN, Rudolf. Rudolf Laban speaks about movement and dance. Lectures and articles selected and edited by Lisa Ullmann. Published by Lisa Ullmann, Laban Art of Movement Centre, Woburn Hill, Addlestone, Surrey, 1971.

Domínio do Movimento. Edição organizada por Lisa Ullman. Tradução de Anna Maria B. De Vecchi e Maria Sílvia M. Netto. São Paulo: Summus, 1978.
A vision of dynamic space. London and Philadelphia: The Falmer Press, 1984.

. Choreutics. Annotated and edited by Lisa UIIman. Hampshire, UK: Dance Books, 2011a.

. The Mastery of Movement. Fourth Edition. Revised by Lisa Ullman. Hampshire, UK: Dance Books, 2011b.

LARROSA, Jorge Bondía. Notas sobre a experiência e o saber de experiência. Tradução de João Wanderley Geraldi. Revista Brasileira de Educação, n. 19, p. 20-28, 2002.

LAUNAY, Isabelle. A la recherche d'une danse moderne: Rudolf Laban et Mary Wigman. Université de Paris 8, Saint-Denis - Département Danse, 1997.

LOUPPE, Laurence. Poética da dança contemporânea. Lisboa: Orfeu Negro, 2012.

MALETIC, Vera. Body, space, expression: the development of Rudolf Laban's movement and dance concepts. Berlin; New York; Amsterdam, Moutande Gruyter, 1987.

MCCAW, Dick. (Org.). The Laban Sourcebook. London and New York: Routledge, 2011.

MERLEAU-PONTY, Maurice. Fenomenologia da Percepção. São Paulo: Martins Fontes, 2006.

RENGEL, Lenira P. Dicionário Laban. São Paulo: Annablume, 2003.

SUQUET, Annie. O corpo dançante: um laboratório da percepção. In: CORBIN, Alain; COURTINE, JeanJacques; VIGARELLO, Georges (Orgs.). História do corpo: as mutações do olhar: o século XX. Tradução de Ephraim Ferreira Alves. 4a Ed. Petrópolis: Editora Vozes, pp. 509-540, 2011.

Recebido: 04/06/2020

Aceito: $31 / 07 / 2020$

Aprovado para publicação: 17/11/2020 
Este é um artigo de acesso aberto distribuído sob os termos de uma Licença Crea- tive Commons Atribuição 4.0 Internacional. Disponível em: $<$ http://creative commons.org/licenses/by/4.0>.

This is an open-access article distributed under the terms of the Creative Commons Attribution License 4.0 International. Available at: <http://creative commons.org/licenses/by/4.0>.

Ce texte en libre accès est placé sous licence Creative Commons Attribution 4.0 International. Disponible sur: <http://creativecommons.org/licenses/by/4.0>. 